\title{
Immediate sequential bilateral intravitreal injections: an Indian perspective
}

This article was published in the following Dove Press journal:

Clinical Ophthalmology

6 April 2017

Number of times this article has been viewed

\section{Koushik Tripathy}

Department of Vitreoretina and Uvea, ICARE Eye Hospital and Postgraduate Institute, Sector-26, Noida,

Uttar Pradesh, India
Correspondence: Koushik Tripathy Department of Vitreoretina and Uvea, ICARE Eye Hospital and Postgraduate Institute, E3A, Sector-26, Noida 20I30I, Uttar Pradesh, India

Tel+9l I202555969

Email drkoushiktripathy@icarehospital.org

\section{Dear editor}

Recently, Ruão et al ${ }^{1}$ have shown in a study spanning 6 years that only 1 of 6560 $(0.015 \%)$ eyes undergoing unilateral intravitreal anti-vascular endothelial growth factor (anti-VEGF) injection developed culture-proven endophthalmitis. None of the 1612 eyes receiving immediate sequential bilateral intravitreal treatment (ISBIVT) with anti-VEGF injection developed endophthalmitis. ${ }^{1}$ Likewise, immediate sequential bilateral cataract surgery (ISBCS) ${ }^{2}$ has been proposed to provide "potentially decreased wait times for surgery, patient convenience and cost savings for health care payors", with comparable visual outcomes and complication rates. However, in an Indian scenario, there is need for discussion regarding endophthalmitis following ISBIVT injections.

According to the guidelines of the All India Ophthalmological Society (AIOS) ${ }^{3}$ for intravitreal injections, "It is recommended to do the injection procedure in an operation theater or a sterile room designated for such procedures taking all precautions as are taken for any intraocular surgery. We do not recommend intravitreal injection Bevacizumab in an office setting". According to this guideline, "bilateral injections are NOT recommended and injection for the other eye should be planned at least one week later". ${ }^{3}$ This guideline was framed following an unfortunate episode of cluster endophthalmitis in the state of Gujarat, India, after the use of intravitreal bevacizumab (IVB). Subsequently, the use of IVB was banned by the Drug Controller General of India in January 2016. However, after multiple meetings between leaders from AIOS and the Vitreoretinal Society of India and officials from the Government of India, the ban was withdrawn in March 2016. In an Indian scenario, the risk of bilateral endophthalmitis following ISIBT injections, - though small, cannot be ignored, given the fact that many patients receiving the injections already have very good visual acuity before the injection. It may invite medicolegal problems for the practicing ophthalmologist also. Tabatabaii et $\mathrm{al}^{4}$ have reported 2 cases of bilateral endophthalmitis caused by Staphylococcus epidermidis after IVB; one patient achieved 20/400 visual acuity in both eyes, while the other patient did not improve from the perception of light bilaterally. Even with current advances in management, the visual outcome of endophthalmitis remains poor, and the patient with endophthalmitis caused by Streptococcus pneumoniae in the current series reported by Ruão et $\mathrm{al}^{1}$ achieved only 20/500 visual acuity. However, another large series from New York $^{5}$ on ISBIVT anti-VEGF injection reported that the incidence of culture-proven endophthalmitis was $0.065 \%$ ( 2 of 3068 total injections), and all such cases improved to preinjection visual acuity. The rate of infectious endophthalmitis after intravitreal anti-VEGF injections has been noted to reach up to $0.078 \% .^{1}$ Thus, 
the available literature ${ }^{1,5}$ on large series of patients undergoing ISBIVT injections suggests similar complication rates and safety levels compared to unilateral anti-VEGF injections, although thorough and individualized consideration of patient safety and local regulations may be needed before performing ISBIVT injections in clinical practice.

\section{Disclosure}

The author reports no conflicts of interest in this communication.

\section{References}

1. Ruão M, Andreu-Fenoll M, Dolz-Marco R, Gallego-Pinazo R. Safety of bilateral same-day intravitreal injections of anti-vascular endothelial growth factor agents. Clin Ophthalmol. 2017;11:299-302.
2. Singh R, Dohlman TH, Sun G. Immediately sequential bilateral cataract surgery: advantages and disadvantages. Curr Opin Ophthalmol. 2017; 28(1):81-86.

3. Kumar A, Verma L, Aurora A, Saxena R. AIOS-VRSI Guidelines for Intravitreal Injections; 2016. Available from: http://aios.org/avguidelines.pdf. Accessed March 20, 2017.

4. Tabatabaii A, Ahmadraji A, Khodabande A, Mansouri M. Acute bilateral endophthalmitis following bilateral intravitreal bevacizumab (avastin) injection. Middle East Afr J Ophthalmol. 2013;20(1):87-88.

5. Lima LH, Zweifel SA, Engelbert M, et al. Evaluation of safety for bilateral same-day intravitreal injections of antivascular endothelial growth factor therapy. Retina. 2009;29(9):1213-1217.

Dove Medical Press encourages responsible, free and frank academic debate. The content of the Clinical Ophthalmology 'letters to the editor' section does not necessarily represent the views of Dove Medical Press, its officers, agents, employees, related entities or the Clinical Ophthalmology editors. While all reasonable steps have been taken to confirm the content of each letter, Dove Medical Press accepts no liability in respect of the content of any letter, nor is it responsible for the content and accuracy of any letter to the editor.

\section{Publish your work in this journal}

Clinical Ophthalmology is an international, peer-reviewed journal covering all subspecialties within ophthalmology. Key topics include: Optometry; Visual science; Pharmacology and drug therapy in eye diseases; Basic Sciences; Primary and Secondary eye care; Patient Safety and Quality of Care Improvements. This journal is indexed on

Submit your manuscript here: http://www.dovepress.com/clinical-ophthalmology-journal
PubMed Central and CAS, and is the official journal of The Society of Clinical Ophthalmology (SCO). The manuscript management system is completely online and includes a very quick and fair peer-review system, which is all easy to use. Visit http://www.dovepress.com/ testimonials.php to read real quotes from published authors. 